arranging for students to attend locally available laboratories at these times.

Access to laboratories is also a problem for the scientific staff, who are expected to continue their research activities in order to keep up with advances in their subject. This is a laudable intention, but in practice it seems that the tight schedule for preparing, testing and revising courses will leave little time for research work, at least in the early years. There is, too, the problem of teaching and doing research in widely separate places, which is why plans are afoot to build a laboratory at Milton Keynes principally for the use of the sixteen full-time scientific staff.

One of the more delicate problems now to be faced must be that of appearing to differ sufficiently from conventional universities, despite the recent acquisition of such traditional pieces of costume as examinations, entrance qualifications-even if disguised-and a vice-chancellor. It is only to be expected that those who are accepted by the university will want its degrees to carry a prestige not too far removed from those conferred elsewhere, while those who are denied entrance will complain of unfair discrimination. So far, the planners seem resolved to avoid too much aping of old ways: "The principle of the Open University is a major innovation in education; so must be its practice" (The Open University, HMSO, 1969). The "systemsanalysis approach to learning" that the planning committee advocates is certainly better than nothing, but mere obeisance to the current catchwords of what is known as educational technology should not conceal the considerable demands of such catchwords as programmed instruction, learning modules and integrated educational systems. These techniques, if properly applied, consume more time and thought than the present staff may be able to give. But the apparent lack of planning information is not a good omen for the future. Between 34,000 and 150,000 students are expected. to enrol, but no clues seem to have been gathered as to the courses they intend to follow, and hence of the right number of staff to employ in each discipline. In short, the university is within sight of opening, but it is still as much a brave promise as a reality.

\section{CARBON FIBRES}

\section{Problems of Exploitution}

When three scientists at the Royal Aircraft Establishment at Farnborough discovered in 1963 a method of producing strong stiff carbon fibres, they set in motion changes which could eventually affect the whole of engineering. Meanwhile, there is for Britain the mundane but pressing problem of ensuring that the discovery is exploited in the way which will bring the greatest profit to the national economy. Doubts about this inspired the Select Committee of the House of Commons on Science and Technology to investigate the arrangements for exploitation; the report of the sub-committee, just published, suggests that there are, indeed, some grounds for concern.

The committee's deliberations hinged on the part played by the National Research Development Corporation. NRDC, the normal agency for handling patents which result from work in government establishments, has licensed three companies (Courtaulds, Rolls-Royce, and the Morgan Crucible Company) to develop carbon fibres and their applications. All three companies had in fact taken an interest in the work for some time before the licences were agreed, and the NRDC seems not to have had a great deal of choice. Both Courtaulds and Morgan have now reached agreement with American companies for the exploitation of carbon fibres in the US market. Morgan has set up a joint company with the Whittaker Corporation of Los Angeles to manufacture carbon fibres in the US, while Courtaulds has granted Hercules Inc., of Delaware, an exclusive licence to sell Courtaulds' fibre there, with an option to manufacture it later. If this latter option is taken up, the agreement provides for a twoway flow of information between Hercules and Courtaulds.

What the sub-committee had to decide was whether or not these arrangements are to Britain's best advantage. Quite clearly, it is impossible to prevent American companies from developing carbon fibre technology. As Mr J. C. Duckworth of NRDC told the committee: "There is no prospect of keeping American producers out of the market indefinitely. This is just not possible for a number of reasons. . . I I suppose the main thing is the Buy American Act, and the second is the real prospect that eventually Americans will find ways of making carbon fibres without infringing our patents; and, thirdly, Americans will infringe if necessary. I do not know if any committee members have knowledge of suing the American Government for infringement." The best thing to do, Mr Duckworth said, was to arrange the licensing agreements so that a full flow-back of American experience is provided in return for the information given to them. This is why the NRDC decided to license the American companies through the British licensees rather than directly, although direct licences would have been more profitable for NRDC itself.

But not everybody is happy with the arrangement. The Ministry of Technology told the sub-committee that in future it would examine very carefully any information supplied by government establishments to the firms concerned, "on the assumption that it will ultimately go across to America". So long as the licences cover only the carbon fibre manufacturing process, there is no problem; this information is now all published, in the form of a patent. (Whether or not the patent is watertight will not be known, of course, unless it is tested in the courts.) But information about composite technology generally poses a more difficult question. The committee recommends that this sort of information should be provided only to composite users like Rolls-Royce, which will pass it on "only if it helps to promote their overall commercial interest". Courtaulds and Morgan, which have only an indirect interest in composite technology, should not therefore be privy to it.

The sub-committee also says that the decision about which firms have access to composite know-how should be made by the government establishments themselves, and not by NRDC. This would mean that the appropriate minister would be ultimately responsible for the decision. Presumably NRDC would still be respon- 
sible for negotiating the terms of the licence-a process which seems to take a very long time. Mr Duckworth told the sub-committee that so far none of the three agreements with the companies has actually been signed, an announcement which seems to have caused some concern.

The most substantial of the sub-committee's recommendations is that a large plant for the production of carbon fibres should be built without delay. A plant producing 450 tons a year of carbon fibre should be built jointly by the three licensees, with government support if necessary. If the licensees are unwilling to go ahead, two other possibilities are suggested. One is that the NRDC should look for a further licensee who would be prepared to go ahead; the other, more unlikely, suggestion is that the Atomic Energy Authority should set up its own plant. This would, however, require legislation, so the sub-committee adds that "every effort should be made to ensure that the AEA has a financial interest in a large scale plant", whoever builds it. The sub-committee recognizes that there is a risk in going ahead with a plant "before demand materializes", but is convinced that the economies of scale would reduce prices so quickly that a large market would be created. It seems to have been particularly impressed by a study carried out by AERE Harwell which suggested that a plant producing 450 tons a year could bring costs down to somewhere near $£ 5$ per $1 b$, or even less. Courtaulds was far less optimistic, suggesting a price of between $£ 5$ and $£ 10$ a lb ten years hence; the present price is about $£ 100$ per lb.

\section{ACCELERATORS}

\section{Boosting NINA}

IT is hard to see what the Daresbury Nuclear Physies Laboratory expects to gain from the design study which it has been carrying out for a $15-20 \mathrm{GeV}$ electron synchrotron. The scheme is attractive enough-it makes use of the existing NINA electron synchrotron at Daresbury (Lancashire) as an injector of $3 \mathrm{GeV}$ electrons for the new machine, which would save nearly \&l million-but in the present climate it must be as obvious a non-starter as accelerator designers have produced for years. The plan has been on the stocks for some time now (Nature, 218, 1095; 1968)-it was put forward first in a 1966 Daresbury internal report on large elcctron synchrotrons and then last year in an internal report narrowed down to the scheme involving NINA. But the genesis of the scheme was prompted by the success of the $20 \mathrm{GeV}$ Stanford linear accelerator and the $10 \mathrm{GeV}$ Cornell electron synchrotron, which made clear the need for a machine with the energy of the linear accelerator but with the better duty cycle of the synchrotron, and encouraged Daresbury to drop ideas of building high energy storage rings for NINA and to go in for electron synchrotrons instead. Daresbury has now published a preliminary design study of the work done since last year's internal report on what it calls the "NINA booster".

Two schemes seem to be open for the NINA booster. Both allow for a maximum energy of $20 \mathrm{GeV}$ with a current of at least $1 \mu \mathrm{A}$ and a duty cycle of more than 5 per cent, going up to 20 per cent if the electron energy does not have to be closely defined. The first and cheaper

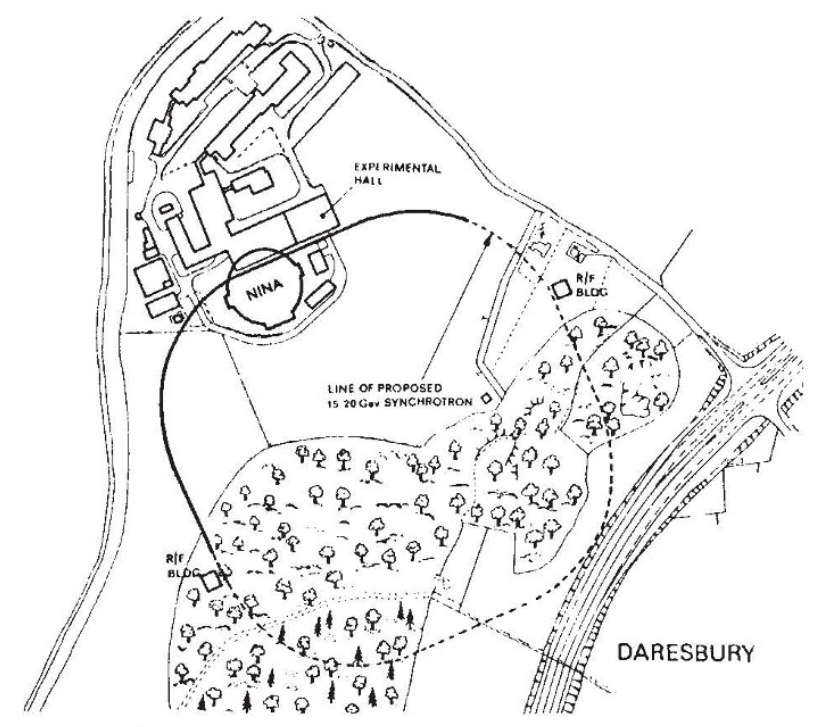

One of the plans for the NINA booster. Dotted line denotes tunnelling.

scheme uses the present experimental halls, but unfortunately involves the new synchrotron cutting across the NINA ring. If the disturbance in the operation of NINA which this would involve is unacceptable, an alternative scheme is possible, but would require new experimental halls. Unfortunately, however, the Daresbury team do not consider in the report what is likely to be the biggest problem of all-where the money will come from. For, although the NINA booster is undoubtedly a cheap way of building a $20 \mathrm{GeV}$ electron synchrotron, the basic scheme, providing $1 \mu \mathrm{A}$ at $15 \mathrm{GeV}$, would cost $£ 3.8$ million, rising to $£ 4.9$ million for $3 \mu \mathrm{A}$ at $20 \mathrm{GeV}$, and $\$ 5.4$ million for the scheme involving least disturbance to NINA. Nor is it obvious how this preliminary study fits in with the SRC's manoeuvrings to join the $300 \mathrm{GeV}$ project by running down the accelerators at Daresbury and the Rutherford High Energy Laboratory, and the intention to reduce the 40 per cent of its funds which goes to nuclear physics.

\section{PHYSICS \\ Instruments on Show}

\section{from a Correspondent}

LABOUR problems almost deprived participants in the 53rd exhibition of scientific instruments and apparatus at the Physics Exhibition this week of the benefits of electricity. Nobody will be surprised that the professional descendants of Faraday managed, for the most part, to mount their exhibits as planned. The Physics Exhibition is always interesting and often a scene of fascinating contrasts. There is something almost whimsical about displaying devices measuring a micro-this or a nano-that in the hall at Alexandra Palace. In the Seientific Instrument Manufacturers Association exhibit next door, incredibly sophisticated clectronic hardware was being explained by demonstrators who were attempting to capture every erratic photon from the Calor gas radiant heaters mounted on obsolete porters' trucks.

The quality of exhibits was well up to the usual standard. If there is a dominant new theme in the 